\title{
Comparative Demographic Traits of the Whitefly (Bemisia tabaci) B Biotype against different Host Plants
}

\author{
Muhammad Farooq ${ }^{1}$, Muhammad Shakeel ${ }^{2 *}$, Umbreen Shahzad ${ }^{3}$, Bilal Saeed Khan ${ }^{4}$, Muhammad Rafiq Shahid ${ }^{5}$, \\ Faisal Hafeez $^{5}$, Misbah Ashraf ${ }^{5}$ \\ ${ }^{I}$ School of Earth, Environment and Biological Sciences, Queensland University of Technology, Brisbane, 4000, Australia, \\ ${ }^{2}$ College of Agriculture, South China Agricultural University, Laboratory of Bio-Pesticide Creation and Application of \\ Guangdong Province, Guangzhou, P. R. China, \\ ${ }^{3}$ College of Agriculture, Bahauddin Zakariya University, Multan (Layyah Sub-Campus), Pakistan, \\ ${ }^{4}$ Department of Entomology, University of Agriculture, Faisalabad, 38000, Pakistan \\ ${ }^{5}$ Ayub Agricultural Research Institute, Faisalabad, Pakistan \\ *For correspondence: faizaneabiwaqas@scau.edu.cn; sanjum2005@gmail.com \\ Received 08 February 2020; Accepted 02 May 2020; Published 10 January 2021
}

\begin{abstract}
The sucking pests, especially whitefly, have damaged various fields and fruit crops across the globe. The study of life-history is of prime importance to monitor the dynamics for preference of a species to its host. This study tested the prevalence and preference of a whitefly species, Bemisia tabaci (Gennadius) B biotype (Hemiptera: Aleyrodidae) on tomato, cotton, pepper, and okra as hosts using age-stage two-sex life table. Results revealed the highest pre-adult developmental duration, survival rate, and fecundity on tomato while the lowest values on okra. Population parameters such as the net reproductive rate $\left(\mathrm{R}_{0}\right)$, intrinsic rate of increase $(r)$, and finite rate of increase $(\lambda)$ were demonstrated longer on cotton and tomato compared to much lower $\mathrm{R}_{0}, r$, and $\lambda$ on pepper and okra. Okra responded significantly differently in the case of the mean generation time, $T$ among all tested genotypes. These findings suggest the possibility of summer vegetables as more favorable hosts for $B$. tabaci. (C) 2021 Friends Science Publishers
\end{abstract}

Keywords: Host plants; Biology; Fecundity; Longevity; Survival; Whitefly

\section{Introduction}

The whitefly, Bemisia tabaci B biotype (Gennadius) (Hemiptera: Aleyrodidae) have become a significant pest for a wide range of agricultural and ornamental plants since the last two decades (Oliveira et al. 2001; Naranjo et al. 2009). The whitefly damages the crop in two ways; one by the nymphs by sucking cell sap and producing honeydew; and the other by the transmission of various viruses to other plants (Jones 2003; Naranjo et al. 2009). The females lay eggs in the groups of 30-40 eggs in patches (Martin et al. 2000). The first instar larvae move to short distances to acquire food sources, but other instars are immobile and are stick to the leaf surface. Their abilities of rapid development, high fecundity, and suitability to adverse living conditions hinder the successful control (Barro et al. 2011; Lu et al. 2012). The un-planned, unnoticed and rigorous use of insecticides has not only created resistance against a broader range of pesticides but triggered many health and environment-related problems. The previous studies only reported the population abundance and management practices of lepidopterous pests, neglected the population ecology of sucking pests (Men et al. 2005). As a result, sucking pests especially $B$. tabaci overwhelmed the management tactics and became a member of the major pest complex (Wu et al. 2002; Akram et al. 2013). As a huge gap has been created, which needs to be addressed by thoroughly understanding the behavior of sucking pests.

The nutritional quality of the host affects the biological parameters of polyphagous insect species (Askoul et al. 2018; Farooq et al. 2018, 2020). The developmental duration, fecundity, and longevity of $B$. tabaci are also strongly influenced by the type of host plant with high nutritional qualities, it provides more food, shelter, and space for ovipositing (Lorenzo et al. 2016). Insects recognize the food quality of a host plant through various stimuli that help to locate the host plants. Different morphological leaf characters such as hair density, shape, and color determine the attractiveness to a pest species (Oriani et al. 2011). The nutritional effects of host plants in various species of whitefly have been studied earlier but very little information is available about the life history parameters of $\mathrm{B}$. tabaci based on age-stage two-sex life table.

The awareness about the life and biology of a pest is

To cite this paper: Farooq M, M Shakeel, U Shahzad, BS Khan, MR Shahid, F Hafeez, M Ashraf (2021). Comparative demographic traits of the whitefly (Bemisia tabaci) B biotype against different host plants. Intl J Agric Biol 25:460-468 
the crucial factor determining its feeding potential. A pest behaves differently at each age and stage in various environments or living conditions (Chi 1990). The implementation of life tables offers a firm understanding of the developmental and reproductive potential of a particular pest under changing living conditions that can be implied in the manipulation of future management strategies (Musa and Ren 2005). Most of the studies utilized traditional female-specific life tables (Birch 1948; Khan et al. 2017) to generate life tables of insect pests under different environmental situations. A female-specific life table does not provide an accurate picture of the population projection of an insect by neglecting the contribution of males and stages in population growth (Birch 1948). The most advanced form of life table is the age-stage two-sex life table developed by Chi (1988) and Chi and Liu (1985) which considers stage differentiation and offers a nearly appropriate estimate of the future population in varying conditions. Unfortunately, the use of the age-stage two-sex life table remained underemphasized to study the biology of sucking pests due to inappropriate handling of a large amount and misinterpretation of data (Samih et al. 2014). Awareness on a large scale is needed to encourage scientists to use advances tools while studying population ecology.

The present studies were aimed to investigate the possibilities of the success of $B$. tabaci on different host plants by taking into account the developmental duration, fecundity, and life table parameters with the help of agestage two-sex life table. This study considered tomato, cotton, pepper, and okra genotypes to compare the success of $B$. tabaci and also performed a population projection analysis to evaluate the future population potential within the specified time.

\section{Materials and Methods}

\section{Host plants and Bemisia tabaci culture}

Four different host plants (tomato, cotton, pepper, and okra) were used in these experiments. The 30 seeds of each genotype were sown in 120 plant pots having $25 \mathrm{~cm}$ diameter filled with compost and perlite substrate and placed under glasshouse conditions $\left(25 \pm 3^{\circ} \mathrm{C}, 60 \pm 5 \mathrm{R}\right.$. H. and photoperiod 16: 8 h L: D) (Azimi et al. 2013). Forty pairs of wild $B$. tabaci adults were initially collected with an aspirator from research farms of Ayub Agricultural Research Institute, Faisalabad, Pakistan and released onto host plants at $4-5$ leaf stage placed in a cubic cage $(30 \mathrm{x}$ $30 \times 30 \mathrm{~cm}^{3}$ ) covered with a fine mesh net (Guo et al. 2014). The plants were watered and fertilized regularly throughout the study period for their proper growth. Three generations of $B$. tabaci were raised on each of the tested host plants under the same conditions before being used for experimentation and to reduce the effect of wild hosts.

\section{Life table studies}

For assessing developmental duration, 1-day old adults collected from culture were shifted on a potted plant placed under the same lab conditions. After $24 \mathrm{~h}$, the leaves were turned to observe eggs with a $10 \mathrm{X}$ hand lens, and adults were removed. A total cohort of 50 eggs was used per treatment. Each egg was circled with the help of a fine nontoxic marker, and all other eggs on leaves were gently removed to maintain the purity of marked leaves. The maximum of five leaves was retained on one plant, each leaf having one egg. Small-numbered tags were hanged around the leaf petiole to indicate each treatment. The same procedure was repeated for first instar nymphs soon after they settled on the leaf. After the establishment of the firstinstar nymph on the leaf, nymphs do not move until the emergence of adults. Moulting and development of each nymph were observed daily with a $10 \mathrm{X}$ hand lens. The leaves were detached at the pupal stage and shifted to plastic cages $(13 \mathrm{~cm} \times 3 \mathrm{~cm})$ covered with a fine mesh net. After the adults' emergence, both sexes were observed daily for oviposition and longevity studies.

\section{Statistical analysis}

The data were analyzed using the TWOSEX-MSChart (Chi 2013). The bootstrap technique with 100,000 replications was applied for the estimation of mean and standard errors for each treatment (Efron and Tibshirani 1993). The Origin 2018 was used to draw the figures. The following parameters were calculated according to respective equations.

The age-specific survival rate $\left(l_{x}\right)$ and age-specific fecundity $\left(m_{x}\right)$ were calculated as:

$$
\begin{gathered}
l_{x}=\sum_{j=1}^{k} s_{x j} \\
m_{x}=\frac{\sum_{j=1}^{k} s_{x j} f_{x j}}{\sum_{j=1}^{k} s_{x j}}
\end{gathered}
$$

Where, $k$ exhibits the number of stages. The net reproductive rate $\left(R_{0}\right)$ was computed as:

$$
R_{0}=\sum_{x=0}^{\infty} l_{x} m_{x}
$$

The intrinsic rate of increase $(r)$ with age indexed from 0 was corrected by the Euler-Lotka equation (Goodman 1982):

$$
\sum_{x=0}^{\infty} e^{-r(x+1)} l_{x} m_{x}=1
$$

The following equation was used for the finite rate of increase $(\lambda)$ :

$$
\lambda=e^{r}
$$

The mean generation time was demonstrated as 


$$
T=\frac{\ln R_{0}}{r}
$$

The life expectancy $\left(e_{x j}\right)$ was determined as:

$$
e_{x j}=\sum_{i=x}^{\infty} \sum_{y=j}^{\beta} s_{i y}
$$

Where, $s_{i y}$ shows the probability of survival of each individual of age $x$ and stage $j$ to age $i$ and stage $y$ by assuming $s_{x j}=1$.

The reproductive rate $\left(v_{x j}\right)$ was assessed according to (Tuan et al. 2014a, b).

$$
v_{x j}=\frac{e^{r(x+1)}}{s_{x j}} \sum_{i=x}^{\infty} e^{-r(i+1)} \sum_{y=j}^{\beta} s_{i y} f_{i y}
$$

\section{Population projection and confidence interval}

The population growth of $B$. tabaci on four different host plants was projected from life table data based by the method of Chi and Liu (1985) and Chi (1990) using TIMING-MSChart (Chi 2017). The bootstrap method with 100,000 repeats was used to determine the variability in population growth of life table parameters. $2.5^{\text {th }}$ and $97.5^{\text {th }}$ percentiles were generated by bootstrap for $R_{0}$ and $\lambda$.

\section{Results}

\section{Developmental time}

The results revealed that the incubation period of $B$. tabaci significantly differed among tested host plants (Table 1). The total pre-adult developmental duration was noted significantly longer on okra than raised on other hosts, while shorter pre-adult developmental duration was observed on tomato. The immature survival rate was recorded higher on tomato and lowest on okra, which significantly differed from other hosts. Female adult longevity remained the greatest on okra and tomato, varying considerably from cotton and pepper. On the other hand, male adult longevity was found to be the longest on tomato whereas the shortest on okra. The results show that females live longer than males. The total longevity on okra was found significantly higher than tested host plants. These results express the suitability and unsuitability of $B$. tabaci on various host plants.

\section{Fecundity and population growth parameters}

The adult pre-ovipositional periods (APOP) and total preovipositional period (TPOP) (Table 1) were estimated significantly longer on okra than other hosts. The feeding of B. tabaci on different host plants reflects that the shortest oviposition duration and the lowest fecundity were recorded on pepper and okra, and the highest fecundity on tomato and cotton, respectively. The same trend was also observed for daily-maximum and life-long fecundity. Based on the mean comparison, results showed that tomato was more susceptible to B. tabaci than other hosts.

Age stage-specific survival rate $\left(s_{x j}\right)$ showed the probability for the survival of freshly laid eggs of $B$. tabaci to each age-stage unit (Fig. 1). The highest survival curve for adult female and male on each cultivar was 0.48 and 0.26 (cotton), 0.34 and 0.28 (pepper), 0.30 and 0.26 (okra), 0.46 and 0.4 (tomato). These values are statistically at par with pre-adult survival rate $(\%)$ of $0.74,0.62,0.56$ and 0.86 respectively (Table 1$)$. The curves not only explain the survivorship but also have overlapping curves showing stage discrepancy, which is an important feature for insects (Fig. 1). The consistency in data represents that adult $B$. tabaci emerged earlier when reared on tomato and survives longer. The $l_{x}, m_{x}$ and $l_{x} m_{x}$ for $B$. tabaci reared on each host plant species showed that the highest peak of $m_{x}$ was noted on tomato at age of $28 \mathrm{~d}$ and the lowest peak was on pepper at the age of $32 \mathrm{~d}$ (Fig. 2).

The age-stage specific life expectancy $\left(e_{x j}\right)$ presents the expected life span of B. tabaci on test hos plants (Fig. 3). The life expectancy of freshly laid eggs on each host plant species was 27.06, 27.1, 27.76, and $27.92 \mathrm{~d}$, respectively which is precisely similar to mean longevity of the whole cohort on each host species, respectively. Life expectancy $\left(e_{x j}\right)$ was decreased with the advancement in age due to in vitro condition which prevented the $B$. tabaci from harsh environmental field conditions. The age-stage specific reproductive value $\left(v_{x j}\right)$ of $B$. tabaci illustrates the contribution of individuals of age $x$ and stage $j$ to the future population (Fig. 4). The reproductive value of $B$. tabaci at the egg stage was almost equal to the finite rate of increase in each host species. The highest reproductive peak of females was observed on tomato at the age of $20 \mathrm{~d}$, while the reproductive peak for pepper was the lowest and found at later age of $26 \mathrm{~d}$. The lower reproductive peak on pepper showed a moderate population increase.

The net reproductive rate $R_{0}$, intrinsic rate of increase $r$, and finite rate of increase $\lambda$ exhibited the lowest and mean generation time $T$ the longest on okra (Table 2). Controversially, B. tabaci reared on tomato revealed the highest $R_{0}, r$ and $\lambda$ and shortest $T$ as compared to other host plants.

\section{Population projection and uncertainty}

The population was projected highest on cotton and expected to increase 25990.63 individuals at the age of 60 , whereas okra predicted the lowest population size of approximately 544.316 individuals at the end of $60 \mathrm{~d}$ (Fig. 5). The variability in the total population size traced at $60 \mathrm{~d}$ projected from the 2.5th and 97.5th percentiles of the finite rate, and the net reproductive rate is demonstrated (Fig. 6).

\section{Discussion}

Developmental and population parameters of insects are affected by different biological, chemical, or physical traits such as plant phenology and secondary compounds. The 
Host Plants Modify the Life History Parameters of Whitefly / Intl J Agric Biol, Vol 25, No 2, 2021

Table 1: Developmental duration, longevity, and fecundity of Bemisia tabaci reared on different host plant species

\begin{tabular}{|c|c|c|c|c|c|c|c|c|}
\hline \multirow{2}{*}{ Developmental duration (d) } & \multirow[b]{2}{*}{$\mathrm{n}$} & \multirow[b]{2}{*}{ Tomato } & \multirow[b]{2}{*}{$\mathrm{n}$} & \multicolumn{3}{|c|}{ Host Plant Species } & \multirow[b]{2}{*}{$\mathrm{n}$} & \multirow[b]{2}{*}{ Okra } \\
\hline & & & & Cotton & $\mathrm{N}$ & Pepper & & \\
\hline Egg & 48 & $3.98 \pm 0.11 \mathrm{~d}$ & 46 & $5.04 \pm 0.08 c$ & 44 & $5.91 \pm 0.11 b$ & 45 & $6.49 \pm 0.11 \mathrm{a}$ \\
\hline N1 & 47 & $3.43 \pm 0.08 c$ & 46 & $3.65 \pm 0.07 b$ & 41 & $3.66 \pm 0.09 b$ & 42 & $4.02 \pm 0.11 \mathrm{a}$ \\
\hline N3 & 45 & $2.42 \pm 0.07 \mathrm{~d}$ & 40 & $2.6 \pm 0.08 c$ & 36 & $3.56 \pm 0.09 b$ & 36 & $4.14 \pm 0.12 \mathrm{a}$ \\
\hline Pupa & 43 & $3.47 \pm 0.08 \mathrm{c}$ & 37 & $3.86 \pm 0.14 b$ & 31 & $5.61 \pm 0.11 \mathrm{a}$ & 28 & $5.61 \pm 0.17 \mathrm{a}$ \\
\hline Total pre-adult & 43 & $15.88 \pm 0.16 \mathrm{~d}$ & 37 & $17.81 \pm 0.21 \mathrm{c}$ & 31 & $22.35 \pm 0.21 b$ & 28 & $23.93 \pm 0.33 a$ \\
\hline Pre-adult survival rate $(\%)$ & & 0.86 & & 0.74 & & 0.62 & & 0.56 \\
\hline \multicolumn{9}{|l|}{ Adult duration (d) } \\
\hline Female adult longevity & 23 & $18.17 \pm 0.29 \mathrm{a}$ & 24 & $17.62 \pm 0.26 b$ & 17 & $17.47 \pm 0.21 b$ & 15 & $18.2 \pm 0.26 a$ \\
\hline Male adult longevity & 20 & $11.6 \pm 0.23 \mathrm{a}$ & 13 & $10.31 \pm 0.36 b$ & 14 & $10.5 \pm 0.25 b$ & 13 & $9.38 \pm 0.27 c$ \\
\hline Total longevity & 43 & $31.02 \pm 0.49 c$ & 37 & $32.86 \pm 0.68 b$ & 31 & $36.68 \pm 0.72 \mathrm{a}$ & 28 & $38.04 \pm 0.96 a$ \\
\hline \multicolumn{9}{|l|}{ Fecundity } \\
\hline APOP & & $2.78 \pm 0.13 b$ & & $2.58 \pm 0.1 b$ & & $2.29 \pm 0.11 \mathrm{c}$ & & $3.13 \pm 0.17 \mathrm{a}$ \\
\hline TPOP & & $18.26 \pm 0.21 \mathrm{~d}$ & & $20.54 \pm 0.31 c$ & & $24.82 \pm 0.33 b$ & & $27.33 \pm 0.51 \mathrm{a}$ \\
\hline Oviposition days & & $12.65 \pm 0.23 a$ & & $12 \pm 0.27 b$ & & $11.82 \pm 0.27 b$ & & $11.73 \pm 0.32 b$ \\
\hline Daily maximum & & 19 & & 16 & & 12 & & 11 \\
\hline Life-long maximum & & 149 & & 127 & & 65 & & 83 \\
\hline
\end{tabular}

Where, N1= $1^{\text {st }}$ Nymphal instar, N2= second nymphal instar, N3= $3^{\text {rd }}$ nymphal instar; TPOP=Total pre-ovipositional period; APOP=Adult pre-ovipositional period. Values are mean \pm S.E; Means within rows followed by the same letter are not significantly different. Standard errors were measured by 200,000 bootstrap resampling
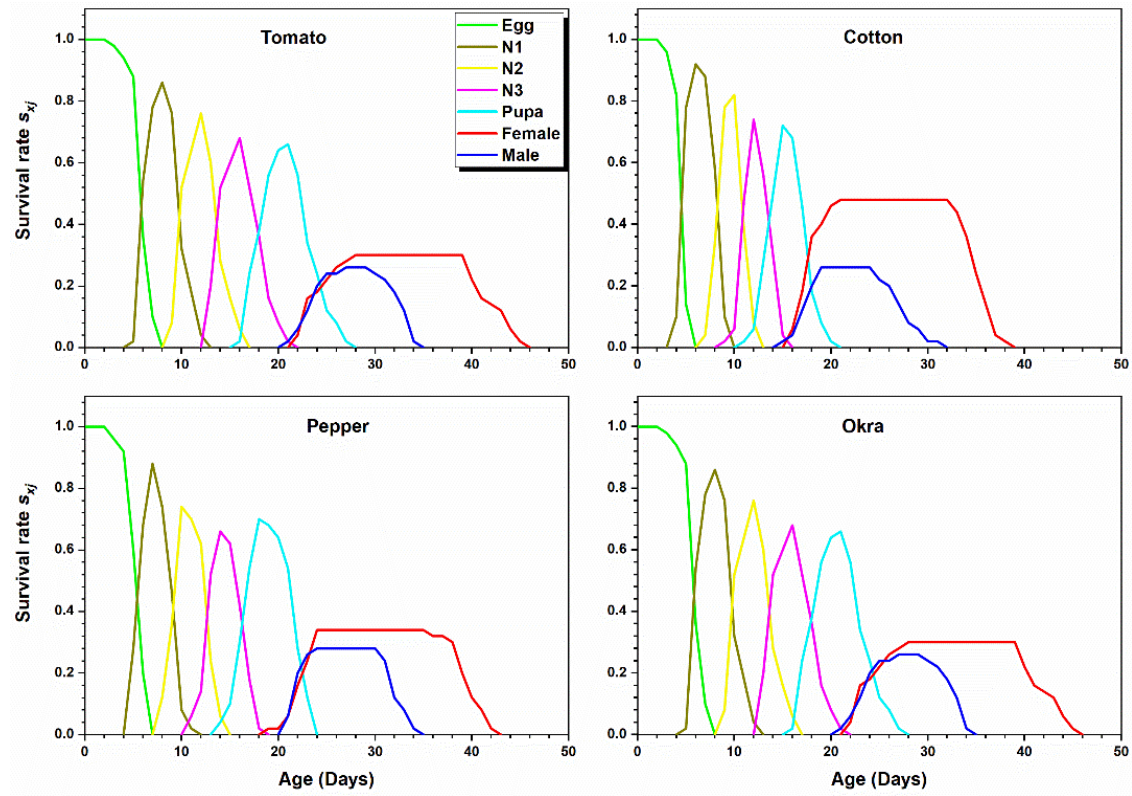

Fig. 1: Age-stage specific survival rate $\left(s_{x j}\right)$ of $B$. tabaci reared on four host plant species

consumption potential of a pest is generally evaluated by developmental or behavioral responses (Phelan et al. 1995; Awmack and Leather 2002; Lee 2007). The use of life tables in determining these responses proved a useful tool to assess the relative acceptance or rejection of host plants by an insect species. Age-stage, two-sex life table has gained much insight among entomologists to evaluate the resistance of different plant genotypes against insect pests and to forecast future pest population peaks compared to female-specific life table (Morris and Miller 1954; Ying et al. 2012). This study also used the age-stage, two-sex life table to assess the plant resistance in four different host plants against $B$. tabaci.
Earlier researchers have reported the effect of host plant species on the development, survival, and fecundity of B. tabaci. The present study results demonstrated that preadult developmental duration was shorter when $B$. tabaci reared on tomato and cotton compared to other hosts. Statistical non-significant differences in population growth of Bemisia argentifolii Bellows \& Perring were observed on cotton, cantaloupe, and pepper cultivars (Nava-Camberos et al. 2001) whereas fluctuating differences were observed when studying the population parameters of $B$. argentifolii on two cultivars of hibiscus (Liu and Stansly 1998). The pre-adult development of $B$. tabaci varied significantly among soybean, cowpea and garden bean (Musa and Ren 

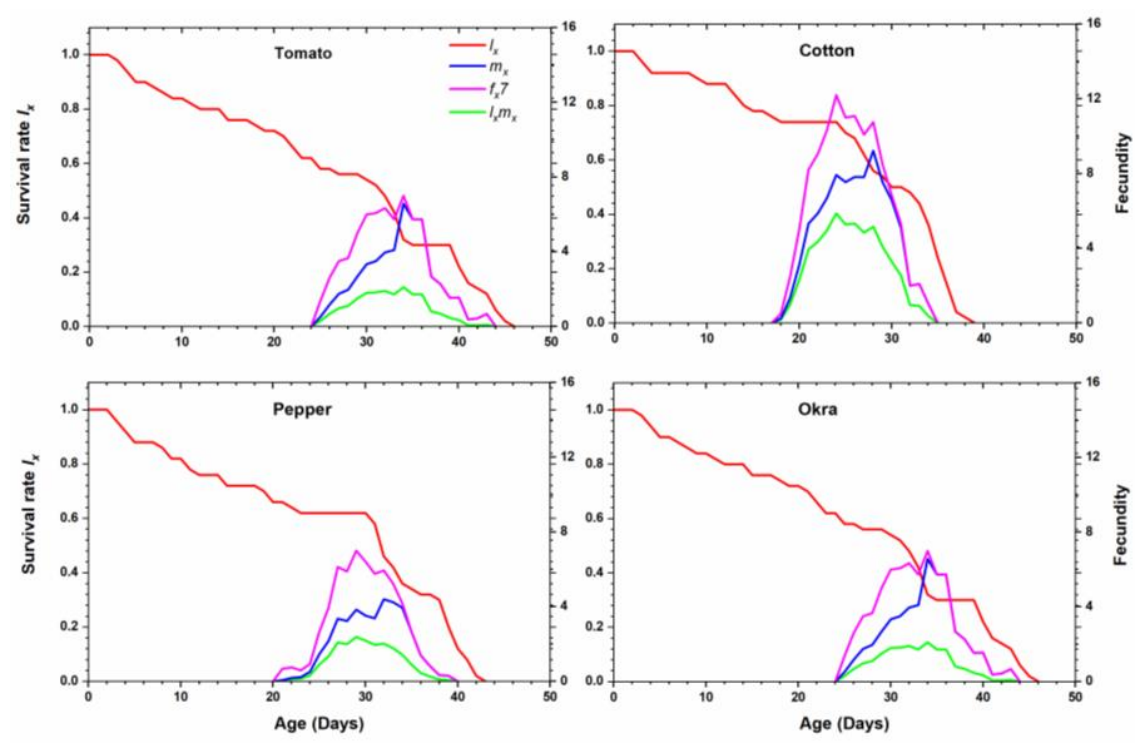

Fig. 2: Age-specific survival rate $\left(l_{x}\right)$, age-stage specific fecundity $\left(f_{x j}\right)$, age-specific fecundity $\left(m_{x}\right)$ and age-specific maternity $\left(l_{x} m_{x}\right)$ of $B$. tabaci reared on four host plant species
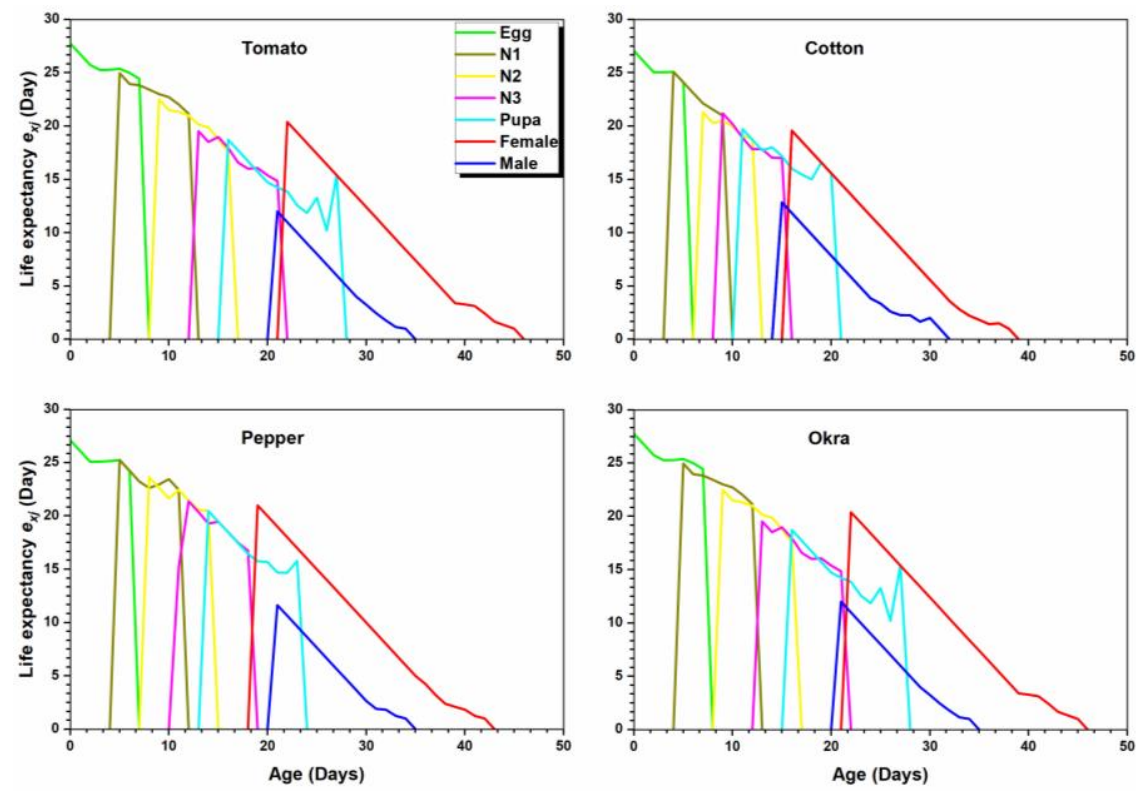

Fig. 3: Age-stage specific life expectancy $\left(e_{x j}\right)$ of B. tabaci reared on four host plant species

2005). In another study, bean cultivars were found more resistant against whitefly, Trialeurodes vaporariorum (West.) (Hemiptera - Homoptera: Aleyrodidae) compared to soybean (Campos et al. 2003).

Life history parameters of $B$. tabaci are affected by host quality, trichome density, and nutritional value of host plants. Mostly, plant species with hairy leaves are preferred by the insects for feeding and as a site for egg holding (Butler et al. 1991; Mcauslane 1996). The resistant cultivars may produce particular kinds of proteins or boost the chlorophyll content to avoid the pest attack and triggering the resistance process (Smith 2005; Bernardi et al. 2012). The present study results demonstrated that pre-adult mortality percentage remained the highest on okra which depicts unfavorable population growth for $B$. tabaci. Male, female and total longevities were found to be significant among tested host species.

Adult pre-oviposition period (APOP), total preoviposition period (TPOP), and fecundity are essential parameters in assessing the potential of an insect pest on specific host plants (Awmack and Leather 2002; Azimi 2016). TPOP is often preferred over APOP; it includes the 
Host Plants Modify the Life History Parameters of Whitefly / Intl J Agric Biol, Vol 25, No 2, 2021

Table 2: Population growth parameters of Bemisia tabaci on different host plant species

\begin{tabular}{llll}
\hline Parameters & \multicolumn{1}{c}{ Host plant Species } & \\
\hline & Tomato & Cotton & Pepper \\
$R o($ offspring/individual) & $56.45 \pm 6.17 \mathrm{a}$ & $55.29 \pm 5.79 \mathrm{a}$ & $20.43 \pm 2.85 \mathrm{~b}$ \\
$T(\mathrm{~d})$ & $23.91 \pm 0.15 \mathrm{~d}$ & $25.71 \pm 0.19 \mathrm{c}$ & $30.52 \pm 0.25 \mathrm{~b}$ \\
$r\left(\mathrm{~d}^{-1}\right)$ & $0.1684 \pm 0.0049 \mathrm{a}$ & $0.1558 \pm 0.0044 \mathrm{a}$ & $0.0985 \pm 0.0048 \mathrm{~b}$ \\
$\lambda\left(\mathrm{d}^{-1}\right)$ & $1.1834 \pm 0.0058 \mathrm{a}$ & $1.1687 \pm 0.0051 \mathrm{a}$ & $1.1035 \pm 0.0053 \mathrm{~b}$ \\
\hline Where $R_{0}=$ Net reproductive rate; $T=$ Mean generation time; $r=$ Intrinsic rate of natural increase; $\lambda=$ Finite rate of increase. Values are mean \pm S.E; Means within rows followed by the &
\end{tabular}
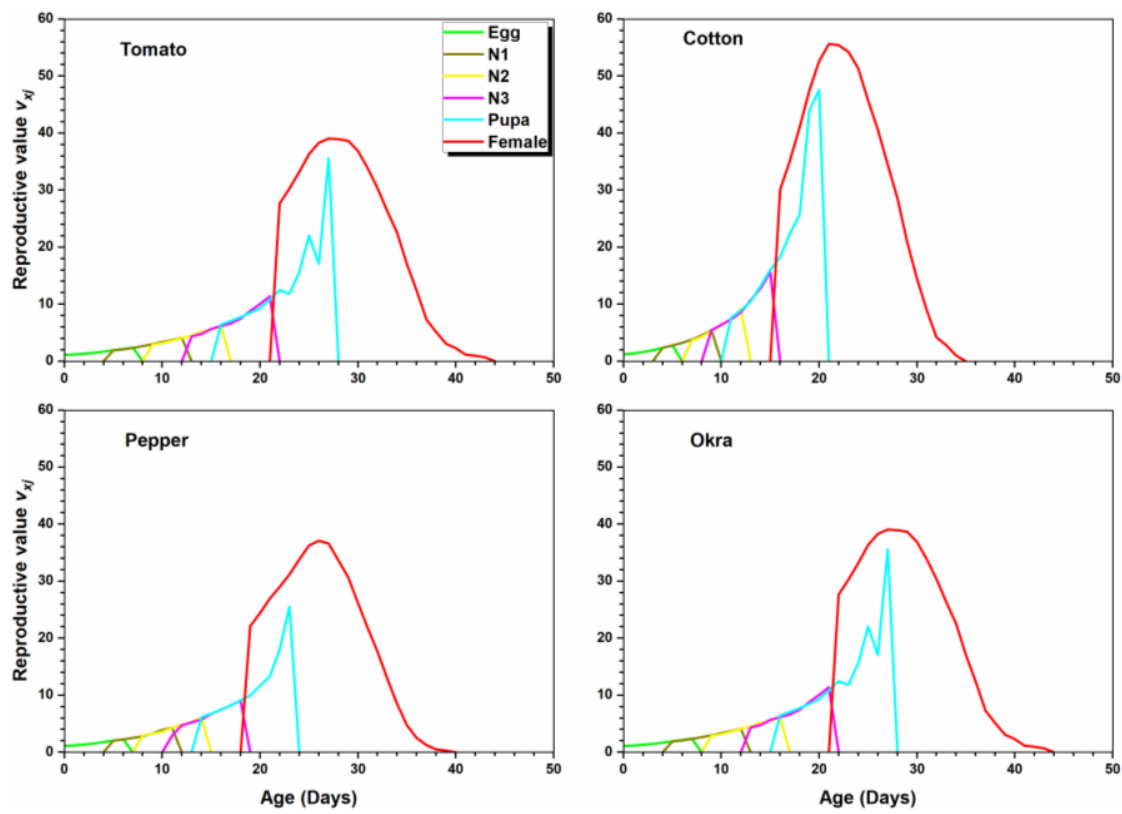

Fig. 4: Age-stage specific reproductive rate $\left(v_{x j}\right)$ of $B$. tabaci reared on four host plant species

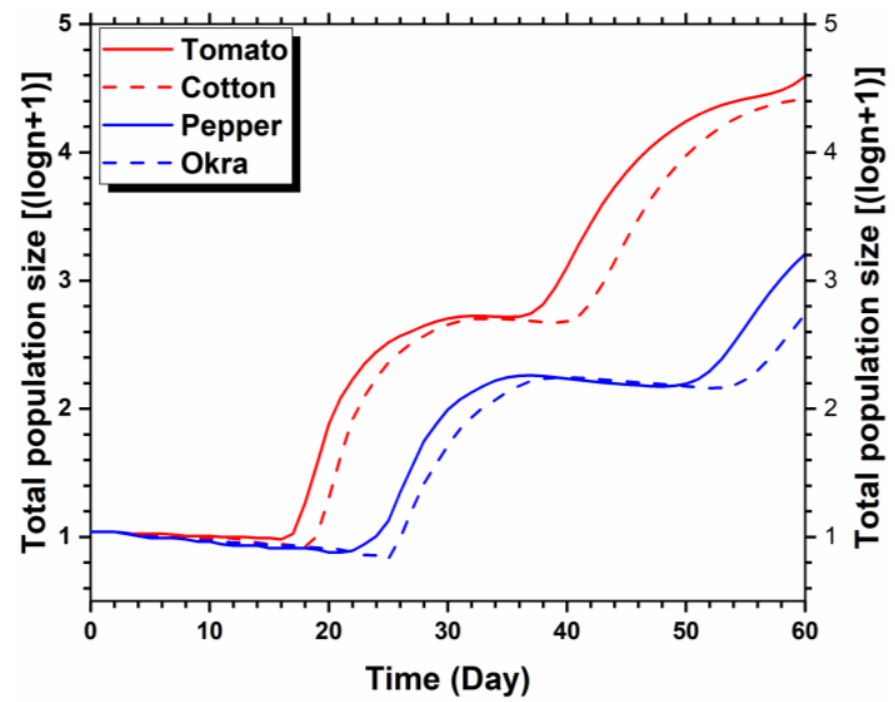

Fig. 5: Comparison of population projections for B. tabaci reared on four host plant species, based on the age-stage, two-sex life table

influence of pre-adult developmental duration on growth rate (Gabre et al. 2005). In present studies, APOP and TPOP differed significantly among tested host species. Okra generated the highest APOP and TPOP. The female fecundity of $B$. tabaci observed on three host species (soybean, cowpea and garden bean) was 160.85, 153.07 and 98, respectively (Musa and Ren 2005). Salas and Mendoza (1995) reported that the egg incubation period of sweet- 

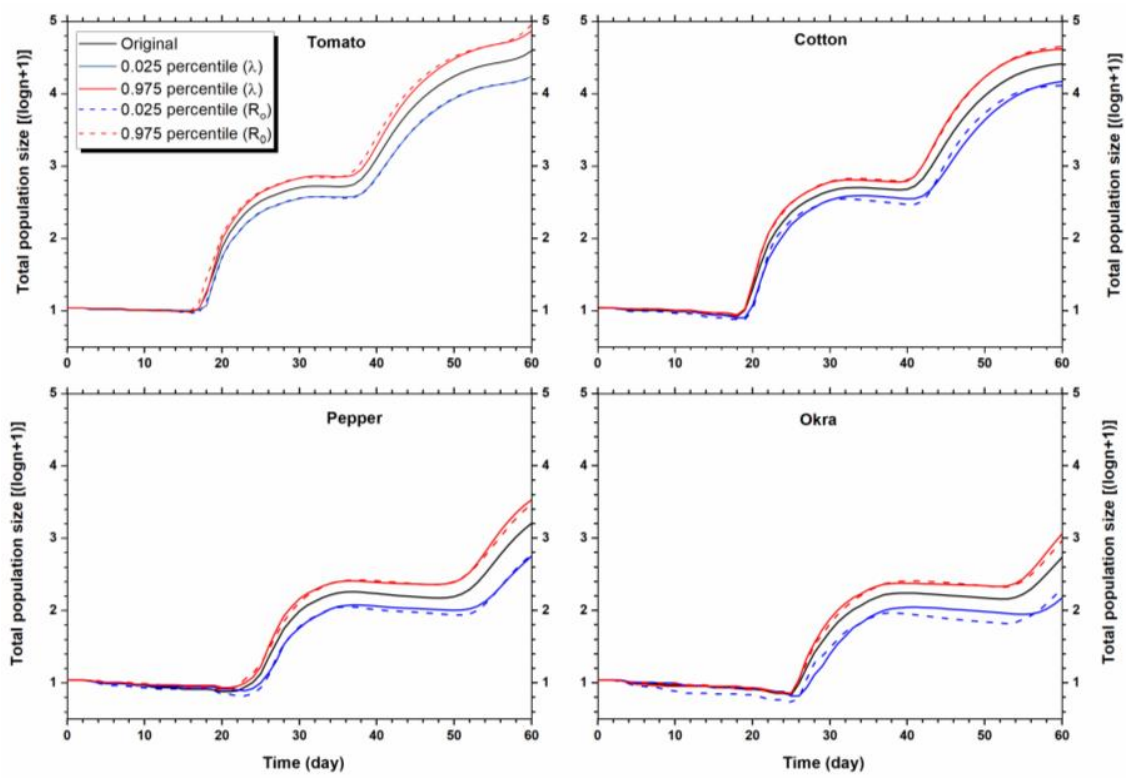

Fig. 6: Population projection of $B$. tabaci reared on four host plant species by using the life tables of the original cohort, the cohorts constructed based on the 2.5 and $97.5 \%$ percentiles of finite rate $(\lambda)$ and net reproductive rate $\left(R_{0}\right)$

potato whitefly varied from 7.3, 4.0, 2.7, 2.5 and 5.8 for the first instar to the pupal stage, respectively. Female and male longevities were recorded as 19.0 and 19.4 days. The female fecundity remained high 194.9 with an $86.5 \%$ survival rate.

The population parameters present a brief idea about the influence of host plants on the population growth rate of a pest insect. The most crucial population parameters include the net reproductive rate $\left(\mathrm{R}_{0}\right)$, mean generation time $(T)$, intrinsic rate of increase (r) and the finite rate of increase $(\mathrm{k})$. The higher values of the population parameters except mean generation time exhibit a large population size (Goundoudaki et al. 2003). The significant differences in these population parameters were demonstrated by two biotypes of B. tabaci reared on G. hirsutum L. and Brassica napus L. (Samih et al. 2014). Musa and Ren (2005) reported that based on population parameters, rapeseed and cotton offered slow development of $B$. tabaci as compared to soybean. Kakimoto et al. (2007) presented that $r$ and $R_{0}$ values of $B$. argentifolii were 0.168 and $185.1 ; 0.153$ and $130.7 ; 0.143$ and 73.1 and 0.110 and 36.1 on eggplant, cucumber, sweet pepper, and tomato, respectively. In present study, the population parameters were significantly different when $B$. tabaci reared on alternative host plant species. The higher net reproductive rate was observed on tomato and lower on okra. The intrinsic rate and the finite rate of increases were found higher among tomato and cotton as compared to other host species. Nonethless, in contradiction to these findings, negative response of different cotton cultivars against B. tabaci has also been reported (Chandi and Kular 2014; Azimi 2016; Pessoa et al. 2016).

Population projection helps in understanding any change in stage structure based on life table data (Chi 1990;
Reddy and Chi 2015). The time of stage emergence of a population can be depicted by the concept of population projection and nowadays it is being used in various pest management strategies (Chi 1990). In a well-structured integrated pest management (IPM program), it is crucial to know about the age-stage specific consumption by a pest, which helps in devising a comprehensive pest control strategy (Huang et al. 2017). The population projection also helps in estimating the fluctuations in the feeding potential of the age-stage structure (Peng et al. 2016). The variability in growth was projected using life table data from $2.5^{\text {th }}$ and $97.5^{\text {th }}$ percentiles of finite rate of increase and the net reproductive rate. It was observed that with the advancement in time, the growth rate of $B$. tabaci stages was approximately equal to the intrinsic rate of increase on the natural logarithm scale (Huang et al. 2017).

\section{Conclusion}

The application of the age-stage two-sex life table to study the behavior of $B$. tabaci concerning different host plants yielded many valuable results. Longer fecundity and population parameters were observed on tomato specifically, with better nutritional qualities as compared to other host plant species. In summary, it was concluded that $B$. tabaci has successfully shifted to agricultural and horticultural crops and has been developed as a significant pest. Therefore, it was concluded that tomato is the most suitable host plant of B. tabaci, albeit, the pest also developed successfully on other hosts like cotton, pepper and okra. It indicates that these hosts might play an important role in the population development, survival and overwintering of $B$. 
tabaci. Therefore, measures should be taken at all levels to combat the attack of this pest. Moreover, the biology of $B$. tabaci should also be studied using an age-stage two-sex life table in varying environmental conditions.

\section{Acknowledgments}

Authors are thankful to the Ayub Agricultural Research Institute, Faisalabad, for the provision of tested host plant species. Authors are also highly indebted to Prof. Hsin Chi, Department of Entomology, National Chung Hsing University, Taiwan, for guidance about the application of the age-stage two-sex life table.

\section{Author Contributions}

MF, MS designed and performed the experiment, BSK, SA and FH supervised the experiments and reviewed the manuscript, MRS analysed the raw data, US and MA helped in manuscript writeup.

\section{References}

Akram M, F Hafeez, M Farooq, M Arshad, M Hussain, S Ahmed, S Zia, HAA Khan (2013). A case to study population dynamics of Bemisia tabaci and Thrips tabaci on Bt and non-Bt cotton genotypes. Pak J Agric Sci 50:617-623

Askoul K, E Richter, S Vidal, I Lusebrink (2018). Life history parameters of Aleyrodes proletella (Hemiptera: Aleyrodidae) on different host plants. J Econ Entomol 112:457-464

Awmack CS, SR Leather (2002). Host plant quality and fecundity in herbivorous insects. Ann Rev Entomol 47:817-844

Azimi S (2016). Effect of Iranian Bt cotton on life table of Bemisia tabaci (Hemiptera: Alyrodidae) and Cry $1 \mathrm{Ab}$ detection in the whitefly honeydew. Arthropods 5:87-96

Azimi S, A Ashouri, M Tohidfar (2013). Two-sex life table of cotton whitefly Bemisia tabaci on two varieties of cotton (Gossypium hirsutum). Intl J Biosci 3:84-89

Barro PJD, SS Liu, LM Boykin, AB Dinsdale (2011). Bemisia tabaci: A statement of species status. Ann Rev Entomol 56:1-19

Bernardi D, MS Garcia, M Botton, DE Nava (2012). Biology and fertility life table of the green aphid Chaetosiphon fragaefolli on strawberry cultivars. J Ins Sci 12; Article 28

Birch L (1948). The intrinsic rate of natural increase of an insect population. J Anim Ecol 17:15-26

Butler JG, F Wilson, G Fishler (1991). Cotton leaf trichomes and populations of Empoasca lybica and Bemisia tabaci. Crop Prot 10:461-464

Campos OR, WB Crocomo, AM Labinas (2003). Comparative biology of the whitefly Trialeurodes vaporariorum (West) (HemipteraHomoptera: Aleyrodidae) on soybean and bean cultivars. Neotr Entomol 32:133-138

Chandi RS, JS Kular (2014). Biological parameters of whitefly, Bemisia tabaci (Gennadius) on $B t$ and non- $B t$ cotton under Punjab conditions. $J$ Exp Zool 17:555-561

Chi H (2017). TIMING-MSChart: A computer program for the population projection based on age-stage, two-sex life table. Retrieved from: http://140.120.197.173/ecology/prod02.htm

Chi H (2013). TWO SEX-MSChart: Computer program for age-stage, twosex life table analysis. Available at: http://140.120.197.173/ecology/prod02.htm

Chi $H$ (1990). Timing of control based on the stage structure of pest populations: A simulation approach. J Econ Entomol 83:1143-1150

Chi H (1988). Life-table analysis incorporating both sexes and variable development rates among individuals. Environ Entomol 17:26-34
Chi H, H Liu (1985). Two new methods for the study of insect population ecology. Bull Inst Zool Acad Sin 24:225-240

Efron B, RJ Tibshirani (1993). An Introduction to the Bootstrap. Chapman \& Hall, New York, USA

Farooq M, X Zhu, M Shakeel, A Iftikhar, MR Shahid, N Saeed, MS Arain (2020). Comparative analysis of the demographic parameters of seven spotted ladybird beetle (Coleoptera: Coccinellidae) reared on various host aphid species. Peer J 8; Article e8313

Farooq M, M Shakeel, A Iftikhar, MR Shahid, X Zhu (2018). Age-stage, two-sex life tables of the lady beetle (Coleoptera: Coccinellidae) feeding on different aphid species. J Econ Entomol 111:575-585

Gabre RM, FK Adham, H Chi (2005). Life table of Chrysomya megacephala (Fabricius) (Diptera: Calliphoridae). Acta Oecol 27:179-183

Goodman D (1982). Optimal life histories, optimal notation, and the value of reproductive value. Amer Nat 119:803-823

Goundoudaki S, JA Tsitsipis, JT Margaritopoulos, KD Zarpas, S. Divanidis (2003). Performance of the tobacco aphid Myzus persicae (Hemiptera: Aphididae) on Oriental and Virginia tobacco varieties. Agric For Entomol 5:285-291

Guo L, Y Wang, X Zhou, Z Li, S Liu, L Pei, X Gao (2014). Functional analysis of a point mutation in the ryanodine receptor of Plutella xylostella (L.) associated with resistance to chlorantraniliprole. Pest Manage Sci, 70:1083-1089

Huang HW, H Chi, CL Smith (2017). Linking demography and consumption of Henosepilachna vigintioctopunctata (Coleoptera: Coccinellidae) fed on Solanum photeinocarpum (Solanales: Solanaceae): With a new method to project the uncertainty of population growth and consumption. $J$ Econ Entomol 111:1-9

Jones DR (2003). Plant viruses transmitted by whiteflies. Eur J Plant Pathol 109:195-219

Kakimoto K, H Inoue, T Yamaguchi, S Ueda, KI Honda, E Yano (2007). Host plant effect on development and reproduction of Bemisia argentifolii Bellows et Perring (B. tabaci [Gennadius] B-biotype) (Homoptera: Aleyrodidae). Appl Entomol Zool 42:63-70

Khan BS, M Farooq, F Hafeez, HAA Khan, M Abbas, A Ghaffar (2017). Temperature dependent life parameters and predatory potential of a stigmaeid mite, Agistemus buntex, Chaudhri against two spotted spider mite, Tetranychus urticae, Dufour. Pak J Agric Sci 54:83-89

Lee KP (2007). The interactive effects of protein quality and macronutrient imbalance on nutrient balancing in an insect herbivore. J Exp Biol 210:3236-3244

Liu TX, PA Stansly (1998). Life history of Bemisia argentifolii (Homoptera: Aleyrodidae) on Hibiscus rosa-sinensis (Malvaceae). Florid Entomol 81:437-445

Lorenzo ME, G Grille, C Basso, O Bonato (2016). Host preferences and biotic potential of Trialeurodes vaporariorum and Bemisia tabaci (Hemiptera: Aleyrodidae) in tomato and pepper. Arth-Plant Interact 10:293-301

Lu Y, K Wu, Y Jiang, Y Guo, N Desneux (2012). Widespread adoption of Bt cotton and insecticide decrease promotes biocontrol services. Nature 487:362-365

Martin JH, D Mifsud, C Rapisarda (2000). The whiteflies (Hemiptera: Aleyrodidae) of Europe and the Mediterranean basin. Bull Entomol Res 90:407-448

Mcauslane HJ (1996). Influence of leaf pubescence on ovipositional preference of Bemisia argentifolii (Homoptera: Aleyrodidae) on soybean. Environ Entomol 25:834-841

Men X, F Ge, CA Edwards, EN Yardim (2005). The influence of pesticide applications on Helicoverpa armigera Hübner and sucking pests in transgenic Bt cotton and non-transgenic cotton in China. Crop Prot 24:319-324

Morris R, C Miller (1954). The development of life tables for the spruce budworm. Can J Zool 32:283-301

Musa PD, SX Ren (2005). Development and reproduction of Bemisia tabaci (Homoptera: Aleyrodidae) on three bean species. Ins Sci $12: 25-30$

Naranjo SE, SJ Castle, PJD Barro, SS Liu (2009). Population dynamics, demography, dispersal and spread of Bemisia tabaci. In: Bemisia: Bionomics and Management of a Global Pest, pp:185-226. Springer, Netherlands 
Nava-Camberos U, DG Riley, MK Harris (2001). Temperature and host plant effects on development, survival, and fecundity of Bemisia argentifolii (Homoptera: Aleyrodidae). Environ Entomol 30:55-63

Oliveira M, T Henneberry, P Anderson (2001). History, current status, and collaborative research projects for Bemisia tabaci. Crop Prot 20:709-723

Oriani MAD, JD Vendramim, CJ Vasconcelos (2011). No-choice ovipositional non-preference of Bemisia tabaci (Gennadius) B biotype on tomato genotypes. Sci Agric 68:147-153

Peng L, Y Miao, Y Hou (2016). Demographic comparison and population projection of Rhynchophorus ferrugineus (Coleoptera: Curculionidae) reared on sugarcane at different temperatures. Sci Rep 6; Article 31659

Pessoa R, GD Rossi, AC Busoli (2016). Transgenic cotton-fed Bemisia tabaci (Gennadius) (Hemiptera: Aleyrodidae) affects the parasitoid Encarsia desantisi Viggiani (Hymenoptera: Aphelinidae) Development. Neotrop Entomol 45:102-106

Phelan P, J Mason, B Stinner (1995). Soil-fertility management and host preference by European corn borer, Ostrinia nubilalis (Hübner), on Zea mays L.: A comparison of organic and conventional chemical farming. Agric Ecos Environ 56:1-8

Reddy GV, H Chi (2015). Demographic comparison of sweet potato weevil reared on a major host, Ipomoea batatas, and an alternative host, $I$. triloba. Sci Rep 5; Article 11871
Salas J, O Mendoza (1995). Biology of the sweet potato whitefly (Homoptera: Aleyrodidae) on tomato. Florida Entomol 78:154-160

Samih MA, M Zarabi, M Yazdani, M Rouhani (2014). Biological traits and life table parameters A and B biotype of Bemisia tabaci (Genn.) on cotton and rapeseed. Braz Arch Biol Technol 57:309-316

Smith CM (2005). Plant Resistance to Arthropods: Molecular and Conventional Approaches, $1^{\text {st }}$ edn. Springer Science \& Business Media, Netherlands

Tuan SJ, CC Lee, H Chi (2014a). Population and damage projection of Spodoptera litura (F.) on peanuts (Arachis hypogaea L.) under different conditions using the age-stage, two-sex life table. Pest Manage Sci 70:805-813

Tuan SJ, NJ Li, CC Yeh, LC Tang, H Chi (2014b). Effects of green manure cover crops on Spodoptera litura (Lepidoptera: Noctuidae) populations. J Econ Entomol 107:897-905

Wu K, W Li, H Feng, Y Guo (2002). Seasonal abundance of the mirids, Lygus lucorum and Adelphocoris spp. (Hemiptera: Miridae) on Bt cotton in northern China. Crop Prot 21:997-1002

Ying W, W Yan, G Qiu, H Zhang, C Ma (2012). Age-stage two-sex life tables of the experimental population of Panonychus ulmi (Acari: Tetranychidae) on apples Malus sieversii subspp. kirghisorum and M. domestica Golden Delicious. Acta Entomol Sin 55:1230-1238 